Check for updates

Cite this: Chem. Commun., 2021, 57,12098

Received 13th September 2021. Accepted 27th September 2021

DOI: $10.1039 / \mathrm{d} 1 \mathrm{cc} 05157 a$

rsc.li/chemcomm

\section{Metal-organic frameworks (MOFs) as host materials for the enhanced delivery of biomacromolecular therapeutics}

\author{
Pei-Hong Tong, (D) ${ }^{a}$ Ling Zhu, ${ }^{a}$ Yi Zang, (D) ${ }^{b}$ Jia Li, (D) *b Xiao-Peng He (D) *a and \\ Tony D. James (D)*cd
}

\begin{abstract}
Biomacromolecular drugs have become an important class of therapeutic agents for the treatment of human diseases. Considering their high propensity for being degraded in the human body, the choice of an appropriate delivery system is key to ensure the therapeutic efficacy of biomacromolecular drugs in vivo. As an emerging class of supramolecular "host" materials, metal-organic frameworks (MOFs) exhibit advantages in terms of the tunability of pore size, encapsulation efficiency, controllable drug release, simplicity in surface functionalization and good biocompatibility. As a result, MOF-based hostguest systems have been extensively developed as a new class of flexible and powerful platform for the delivery of therapeutic biomacromolecules. In this review, we summarize current research progress in the synthesis of MOFs as delivery materials for a variety of biomacromolecules. Firstly, we briefly introduce the advances made in the use of biomacromolecular drugs for disease therapy and the types of commonly used clinical delivery systems. We then describe the advantages of using MOFs as delivery materials. Secondly, the strategies for the construction of MOF-encapsulated biomacromolecules (BiomacromoleculesaMOFs) and the release mechanisms of the therapeutics are categorized. Thirdly, the application of MOFs to deliver different types of biomacromolecules (e.g., antigens/antibodies, enzymes, therapeutic proteins, DNA/RNA, polypeptides, and polysaccharides) for the treatment of various human diseases based on immunotherapy, gene therapy, starvation therapy and oxidation therapy is summarized. Finally, the remaining challenges and available opportunities for MOFs as drug delivery systems are outlined, which we anticipate will encourage additional research efforts directed towards developing Biomacromolecules@MOFs systems for biomedical applications.
\end{abstract}

\section{Introduction}

With the rapid development of modern medical science and technology, the effective treatment of fatal human diseases such as cancer, neurodegenerative disorders and metabolic diseases and their secondary complications remains a global challenge. Over the past few decades, biomacromolecules with

\footnotetext{
${ }^{a}$ Key Laboratory for Advanced Materials and Joint International Research Laboratory of Precision Chemistry and Molecular Engineering, Feringa Nobel Prize Scientist Joint Research Center, School of Chemistry and Molecular Engineering, East China University of Science and Technology, 130 Meilong Rd., Shanghai 200237, China.E-mail:xphe@ecust.edu.cn

${ }^{b}$ National Center for Drug Screening, State Key Laboratory of Drug Research, Shanghai Institute of Materia Medica, Chinese Academy of Sciences, Shanghai 201203, P. R. China.E-mail: jli@simm.ac.cn

${ }^{c}$ Department of Chemistry, University of Bath, Bath, BA2 7AY, UK.

E-mail: t.d.james@bath.ac.uk

${ }^{d}$ School of Chemistry and Chemical Engineering, Henan Normal University, Xinxiang 453007, China
}

therapeutic functions including proteins, peptides, plasmid DNA, small-interfering RNA and polysaccharides have proven to be applicable in various clinical trials for disease therapy. ${ }^{1,2}$ Although biomacromolecular therapeutics have achieved remarkable success in the treatment of diseases, numerous challenges remain. For example, biomacromolecules are unstable during circulation in the blood, are easily degraded by enzymes, display short half-lives, exhibit immunogenicity, and can unselectively interact with healthy cells, and most are unable to cross biological barriers in vivo to reach target cells. ${ }^{3}$ As a result, researchers have developed a diverse range of drug delivery systems to protect biomacromolecules from being denatured and degraded in vivo. In addition, these systems facilitate the controlled release of biomacromolecular therapeutics in target tissues/cells.

Currently used clinical delivery systems can be divided into viral and non-viral vectors. ${ }^{4}$ Compared with non-viral vectors, viral vectors exhibit low target-specificity, are of high cost and exhibit potential biosafety concerns. Non-viral vectors can be sub-divided into organic (e.g., liposomes and hydrogels) and 
inorganic (e.g., silica, carbon materials, inorganic nanoparticles, and organic polymers) carriers. ${ }^{5,6}$ However, problems still exist for non-viral vectors. For example, mesoporous silica displays low encapsulation efficiency, and the loaded guest molecules easily leak out. Inorganic nanoparticles can only adsorb biomacromolecules onto their surfaces through non-covalent bonding or covalent bioconjugation, which leads to minimal protection of biomacromolecules from in vivo degradation. In addition, liposomes as a clinically approved delivery system suffer from some drawbacks such as a low loading capacity for biomacromolecules, ease of oxidation and hydrolysis of phospholipids, and a short half-life. ${ }^{7}$ As a consequence, it is necessary to develop new vector systems for biomacromolecular therapeutics.

Metal-organic frameworks (MOFs) are porous materials formed by the coordination of metal cations/clusters with organic ligands. ${ }^{8,9}$ With the advancement of supramolecular host-guest chemistry, several structurally well-defined functional MOFs have been synthesized. ${ }^{10}$ In a mixed solution containing metal ions and organic ligands, biomacromolecules can be encapsulated into the interior space of a MOF material through self-assembly. Owing to the flexibility of coordination chemistry, such biomacromolecular (guests) can easily fit into the cavity of MOFs (hosts), producing structurally stable host-guest ensembles (Biomacromolecules@MOFs). Alternatively, the pores of mesoporous MOFs that have already been synthesized can be used to directly accommodate biomacromolecules. Using these approaches, the activity of biomacromolecules can be retained with enhanced stability under physiological conditions. ${ }^{11}$ To date, host-guest systems for biomacromolecules based on MOFs are much less explored compared to those based on cyclodextrins, crown ethers and calixarenes. $^{12}$

The main advantages of MOFs as a carrier for biomacromolecules are as follows. ${ }^{13,14}$ (1) An extensive variety of MOF-based functional materials with different sizes, shapes and physical/ chemical properties can be designed and prepared using available metal ions and organic ligands. (2) MOFs exhibit ultrahigh porosity, large specific surface area and adjustable pore size, making them an excellent host matrix for encapsulating biomacromolecules. (3) The active sites that immobilize biomacromolecules are evenly distributed in the pores of MOFs, resulting in reduced drug leakage prior to reaching target tissues/cells. (4) The surface of MOFs is readily modifiable by a diverse range of targeting agents facilitating target-specific drug delivery. (5) MOFs exhibit good biocompatibility and low cytotoxicity and can effectively penetrate the cell membranes of different types of cells including liver cells, $\mathrm{T}$ cells, vascular cells, lung cells, germ cells, pancreatic cells, etc. ${ }^{15-21}$ This is because MOFs exhibit high porosity and large specific surface area, which facilitates enhanced contact with the cell membranes, thereby increasing their uptake by cells. In addition, positively charged MOF materials can bind to cell membranes through electrostatic interactions and thus can enter cells by endocytosis.

In this review, we summarize recent advances in the treatment of human diseases using Biomacromolecules@MOFs (Scheme 1). The host-guest strategies developed for the construction of Biomacromolecules@MOFs are summarized, and the application

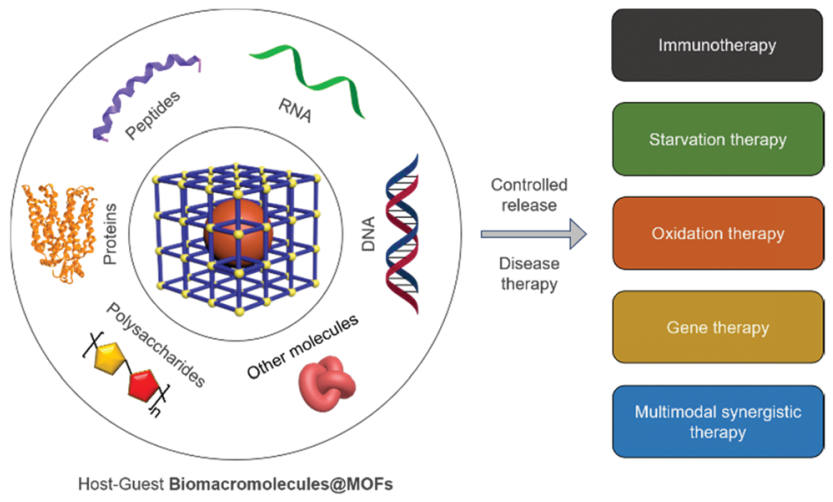

Scheme 1 Biomacromolecules used for the host-guest interaction with metal-organic frameworks (MOFs) (BiomacromoleculesaMOFs) and their application for the controlled release of biomacromolecular therapeutics achieving disease therapy via different therapeutic mechanisms.

of MOFs for the controlled delivery of a diverse range of different biomacromolecules for disease therapy is introduced. Finally, we outline the future opportunities available and remaining challenges for Biomacromolecules@MOFs as delivery vectors.

\section{Host-guest strategies for the synthesis of Biomacromolecules@MOFs and their application in disease therapy}

Biomacromolecular drugs exhibit high therapeutic efficacy for the treatment of a variety of human diseases including microbial infections, autoimmune diseases, metabolic disorders, neurodegenerative diseases and cancer. ${ }^{22-27}$ Compared with traditional small-molecule based drugs, they possess certain advantages over small-molecule based drugs in terms of better target specificity, unique therapeutic function, low susceptibility to multidrug resistance, and fewer side effects that can interfere with normal biological processes; in addition, the research and development cycle of biomacromolecular drugs is generally faster than that of small-molecule based therapeutics. ${ }^{28}$ The biomacromolecules used for disease therapy include DNA/RNA, antigens/antibodies and peptides/polysaccharides. MOFs represent an emerging class of delivery systems with the potential to substantially improve the efficacy of disease therapy. ${ }^{29}$ By using MOFs as the host molecule, biomacromolecules as the guest molecules can be more efficiently delivered to target tissues/cells and achieve enhanced therapeutic effect. The currently reported host-guest strategies to construct Biomacromolecules@MOFs can be divided into two different paths (Fig. 1).

Path (a)

Pore encapsulation is a host-guest strategy for encapsulating biomacromolecules using preformed MOFs. ${ }^{30}$ In recent years, many mesoporous MOFs have been successively used to accommodate biomacromolecular therapeutics based on pore encapsulation. ${ }^{31,32}$ Using this strategy, the pore shape and size of the MOF based material must match the three-dimensional 


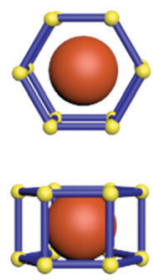

Path (a): Pore encapsulation

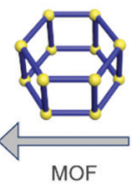

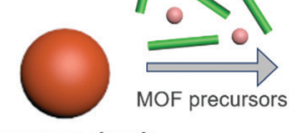
Biomacromolecule
Path (b): In-situ encapsulation

Fig. 1 Host-guest strategies to construct Biomacromolecules@MOFs.

structure of the biomacromolecules of interest to ensure the successful encapsulation. The driving forces by which biomacromolecules are immobilized into the pores of MOFs include van der Waals forces, hydrophobic/hydrophilic and electrostatic interactions, $\pi-\pi$ stacking and hydrogen bonding. Moreover, to achieve pore encapsulation of biomacromolecules, the MOF material used should be soluble and water stable. Although pore encapsulation has been shown to be an effective method for loading biomacromolecules, this strategy has limitations in terms of the loading of large biomacromolecules.

Path (b)

In situ encapsulation is an alternative strategy to pore encapsulation, which can accommodate a broader spectrum of biomacromolecules irrespective of the size of biomacromolecules. ${ }^{33,34}$ The principle of this strategy is that the MOF precursor undergoes a self-assembly process surrounding the biological macromolecules, and then the biomolecules are uniformly encapsulated inside the MOF material to obtain a host-guest supramolecular ensemble. However, only a limited number of MOF based materials have been used for in situ encapsulation of biomacromolecules (e.g., ZIF-8 and ZIF-90). This is because the conditions for synthesizing the MOF must be mild (e.g., low temperature, organic solvents) to ensure that the bioactivity of biomacromolecules is not compromised during the encapsulation process..$^{35-38}$ The above-mentioned conditions hamper the use of a significant number of available MOFs. Furthermore, since in situ generation results in the complete encapsulation of the biomacromolecules within the MOFs, the loaded biomacromolecules can only be released when the MOFs are decomposed.
As such, stimuli-responsive MOFs are the ideal choice for the controlled release of biomacromolecules. ${ }^{39,40}$ When stimulusresponsive MOFs are activated by specific intracellular triggers (e.g., acidic $\mathrm{pH}$, reactive biospecies, ATP, etc.), their host-guest architecture will collapse, thereby releasing the biomacromolecules in a controlled manner.

\subsection{The host-guest materials of Proteins@MOFs}

Therapeutic proteins have unique advantages in disease therapy. ${ }^{41}$ Protein-based drugs can directly induce cancer cell apoptosis through well-defined signaling pathways or indirectly inhibit tumor growth by regulating the tumor microenvironment or by stimulating an autoimmune response. In addition, the use of protein therapy does not modify the genetic information. Table 1 presents representative examples of currently established Proteins@MOFs for human disease therapy. ${ }^{42-53}$

2.1.1 Enzymes@MOFs. Enzymes have attracted significant interest in the field of disease therapy because of their high specificity and functional diversity. ${ }^{54}$ To date, therapeutic enzymes approved by the FDA include caspase-3, RNase, granzyme, glucose oxidase (GOx), asparaginase and CRISPR/Cas9. ${ }^{55,56}$ Since the therapeutic targets of most anticancer enzymes are located within cells, the effective delivery of these enzymes inside cancer cells is a key factor for their therapeutic efficacy.

Enzymes@MOFs materials are mainly prepared by the pore encapsulation strategy. For example, Ma et al. immobilized microperoxidase-11 (MP-11) into the pores of a mesoporous MOF. ${ }^{57}$ The selected Tb-TATB materials had pore sizes ranging from $3.0 \mathrm{~nm}$ to $4.1 \mathrm{~nm}$, which provided sufficient space to accommodate MP-11 with a size of approximately $3.3 \times 1.7 \times$ $1.1 \mathrm{~nm}^{3}$. The host-guest MP-11@Tb-TATB material exhibited an excellent enzymatic activity. In addition, they reported that cytochrome $c$ (Cyt $c$ ) could also enter the cavity of mesoporous MOFs, even though the size of the enzyme was larger than that of the MOF pore ${ }^{58}$ This suggests that the conformation of the Cyt $c$ enzyme molecule changed after being loaded into the MOFs, which might be caused by the surface contact of the enzyme with the MOF crystal. It was proposed that the tertiary structure of the protein undergoes partial unfolding to pass through the small pores of the nanocage.

Table 1 The application of Proteins@MOFs in disease therapy ${ }^{a}$

\begin{tabular}{|c|c|c|c|c|c|c|}
\hline Host & Guest & Size of composite particle & Release mechanism & Targeted cell lines & Type of disease & Ref. \\
\hline NMIL-100 & GOx & $\sim 203 \mathrm{~nm}$ & GSH & $4 \mathrm{~T} 1$ cells & Breast cancer & 43 \\
\hline ZIF-90 & RNase A-NBC, CRISPR/Cas9 & $429 \pm 27 \mathrm{~nm}, 583 \pm 18 \mathrm{~nm}$ & ATP & HeLa cells & Cervical cancer & 44 \\
\hline $\mathrm{Fe}(\mathrm{SS}) \mathrm{MOF}$ & GOx & $\sim 190 \mathrm{~nm}$ & GSH & 4T1 cells & Breast cancer & 46 \\
\hline ZIF-8 & GOx, CPO & $\sim 150 \mathrm{~nm}$ & pH & 4T1 cells & Breast cancer & 47 \\
\hline ZIF-8 & $\begin{array}{l}\text { Klenow (exo-)fragment } \\
\text { polymerase }\end{array}$ & $162 \pm 25 \mathrm{~nm}$ & $\mathrm{pH}$ & $\begin{array}{l}\text { HeLa cells, } \\
\text { MCF-7 cells }\end{array}$ & Cancer & 48 \\
\hline ZIF-8 & Cas9/sgRNA & $\sim 100 \mathrm{~nm}$ & $\mathrm{pH}$ & CHO cells & n. a. & 50 \\
\hline NU-1000, PCN-222 & Insulin & $\sim 180 \mathrm{~nm}, \sim 210 \mathrm{~nm}$ & Phosphate & SKOV-3 cells & n. a. & 51 \\
\hline MIL-100 & Anti-EpCAM antibody & $\sim 110 \mathrm{~nm}$ & $\mathrm{pH}$ & MCF-7 cells & Cancer & 52 \\
\hline ZIF-8 & Insulin/GOx & $\sim 500 \mathrm{~nm}$ & Glucose & n. a. & Diabetes & 53 \\
\hline
\end{tabular}

${ }^{a}$ n. a. = not available. 


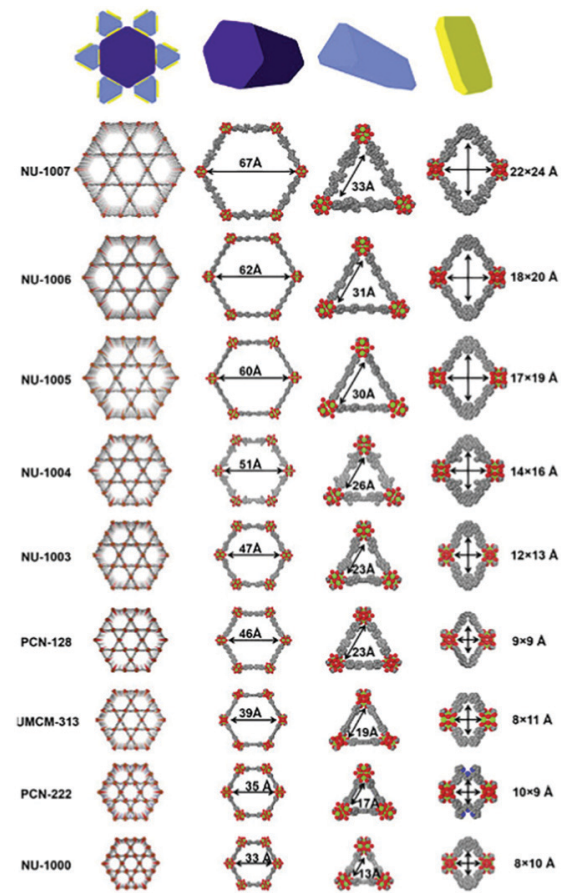

Fig. 2 Comparison of the pore size in different zirconium-based MOFs. Reprinted with permission. ${ }^{59}$ Copyright 2021 Elsevier.

Li et al. further developed a series of mesoporous Zr-based MOFs (NU-100x, $x=3,4,5,6,7$ ) with pore sizes of $3.3 \mathrm{~nm}$ to $6.7 \mathrm{~nm}$ by precisely controlling the torsion angle associated with the organic ligand (Fig. 2). ${ }^{59}$ The extended NU-100x MOF structure was used to encapsulate lactate dehydrogenase (LDH), in which the larger channels were used to immobilize $\mathrm{LDH}$, and the smaller channels and cavities facilitated the free diffusion of substrates and coenzymes. As such, the cascadereaction activity of LDH@Nu-100x was demonstrated to be higher than that of free enzymes.

Effective delivery and lysosomal release of enzymes in living cells remains a big challenge for protein therapeutics. As such, Chu et al. reported Caspase-3@MOFs as a universal strategy for the lysosomal delivery of enzymes (Fig. 3).$^{60}$ Caspase-3, an important

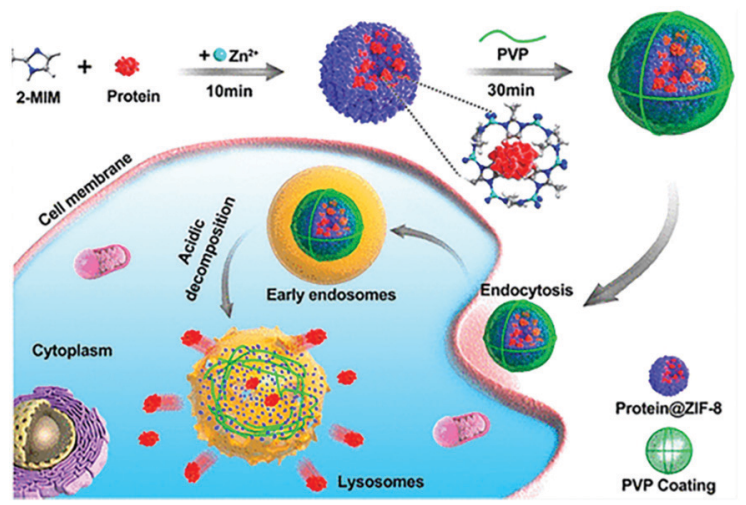

Fig. 3 The construction of CRISPR/Cas9@ZIF- 8 and its pH-controlled drug delivery in cells. Reprinted with permission. ${ }^{60}$ Copyright 2018 American Chemical Society. enzyme implicated in cell apoptosis, ${ }^{61}$ and 2-methylimidazole were pre-mixed, followed by slow addition of a $\mathrm{Zn}^{2+}$ solution. Then, polyvinylpyrrolidone (PVP) was added to modify the surface of the resulting caspase 3@ZIF-8, enhancing the stability of the carrier. Cellular experiments indicated that the ZIF-8 could release the encapsulated caspase- 3 molecules under acidic conditions, inducing cell apoptosis. In order to further improve the targeted delivery of enzymes, Zhang et al. designed lysosomal-responsive nanoparticles (LYS-NPs) loaded with anti-cancer enzymes. With this research, perforin and granzyme B were co-loaded into the interior of ZIF-8 by in situ encapsulation, and then calcium ions were adsorbed onto the surface of ZIF- $8\left(\mathrm{Ca}^{2+}\right.$ is known to enhance the efficacy of perforin and granzyme B). ${ }^{62}$ Finally, a CD63 aptamer was coated onto the surface of the carrier as a targeting agent for the lysosomes of $\mathrm{T}$ cells. LYS-NPs were internalized by $\mathrm{T}$ cells, releasing the therapeutic agents in a pH-controlled manner within the lysosomes. Subsequently, when the major histocompatibility complex (MHC) of cancer cells activated the $\mathrm{T}$ cells, perforin, granzyme $\mathrm{B}$, and $\mathrm{Ca}^{2+}$ were released from the lysosomes to kill the cancer cells. In vivo tests using breast cancer tumor-bearing mice indicated that treatment with $\mathrm{T}$ cells preloaded with LYS-NPs significantly suppressed the tumor growth with an inhibition of $70 \%$. In contrast, the inhibition of $\mathrm{T}$ cells without the MOF pretreatment was only $27 \%$.

In recent years, biomimetic nanoparticles based on the surface coating of natural cell membranes have emerged as a promising strategy for disease therapeutics and vaccination. ${ }^{63}$ By introducing cell membranes to the surface of MOFs, the resulting delivery system can be used for homotypic targeting exhibiting low immunogenicity, which is a key requirement for personalized medicine. ${ }^{64}$ Zheng et al. designed a biomimetic host-guest nanosystem, in which gelonin (a plant toxin) was loaded into the interior of the ZIF-8 material using in situ encapsulation. Then, the membrane of MDA-MB-231 (human breast adenocarcinoma) cells was coated onto the surface of Gelonin@ZIF-8 to target breast cancer. ${ }^{65}$ The ZIF-8 exhibited an encapsulation efficiency of $\sim 94 \%$ and a loading efficiency of $\sim 41 \%$ for gelonin. In vitro and in vivo studies indicated that the Gelonin@ZIF-8/MDA-MB-231 cell membrane system protected the therapeutic proteins from protease digestion, evaded immune clearance, and promoted gelonin uptake by tumor cells. The internalized gelonin induced cell apoptosis by hydrolysis of rRNAs to disrupt protein synthesis. With the help of the biomimetic hostguest nanosystem, the therapeutic effect was increased 11-fold when compared to gelonin alone.

Similarly, Khashab et al. used the Michigan Cancer Foundation-7 (MCF-7) cell membrane of human breast cancer to functionalize a MOF delivery system (Fig. 4). ${ }^{66}$ A CRISPR/ Cas9 genome editing system was loaded into the interior of ZIF-8 using in situ encapsulation to obtain the CRISPR/Cas9@ZIF-8 material (CC-ZIF). Then CC-ZIF was coated with the MCF-7 cell membrane resulting in a particle size of $\sim 150 \mathrm{~nm}$. Amongst different cancer cells including MCF-7, the human cervical cancer Henrietta Lacks (HeLa) cell line, Human Dermal Fibroblast (HDFn) cells and activated Jurkat cells (ATC), the $\mathrm{C}^{3}-\mathrm{ZIF}_{\mathrm{MCF}}$ materials exhibited the highest uptake efficiency in MCF-7 cells. 


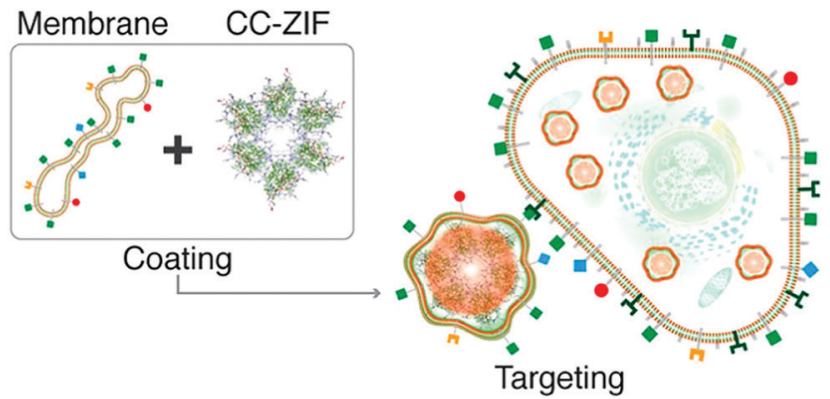

Fig. 4 The preparation of $C^{3}$-ZIF and its targeted entry into cells. Reprinted with permission. ${ }^{66}$ Copyright 2020 American Chemical Society.

Subsequently, the authors demonstrated that the $\mathrm{C}^{3}-\mathrm{ZIF}_{\mathrm{MCF}}$ system significantly suppressed a model transfected gene (enhanced green fluorescent protein) exhibiting a 3-fold improved efficiency when compared with $\mathrm{C}^{3}-\mathrm{ZIF}_{\mathrm{HeLa}}$. This biomimetic method enabled the specific targeting of cancer cells which should facilitate the clinical transformation of such gene-editing technology in the future.

In addition to enzymes that directly kill cancer cells, those that play a complementary role with therapeutic agents have been used for MOF-based delivery systems. ${ }^{67,68}$ Tyrosinase (TYR) can activate the prodrug paracetamol in cancer cells. This process is accompanied by the production of reactive oxygen species (ROS) and the consumption of glutathione, while the enzymatically cleaved product (4-acetamido-o-benzoquinone) has a good therapeutic effect on drug-resistant cancer cells. Zhou et al. chose PCN-333(Al) as a carrier for TYR, which has the advantage of good enzyme loading capacity, simplicity of modification with fluorophores, and good chemical stability under a cellular environment. ${ }^{69}$ In addition, the MOF has two mesoporous cavities with diameters of 4.2 and $5.5 \mathrm{~nm}$, respectively (Fig. 5). The host-guest materials TYR@PPCN-333 (Al) were obtained by encapsulating TYR within the larger mesopores $(5.5 \mathrm{~nm})$ of PPCN-333 (Al). The combined use of

(a)

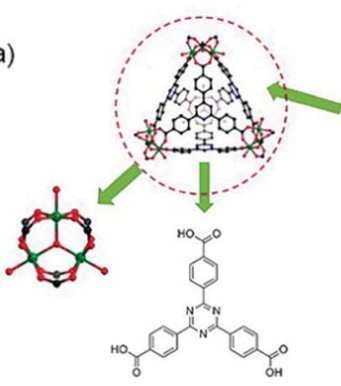

(b)

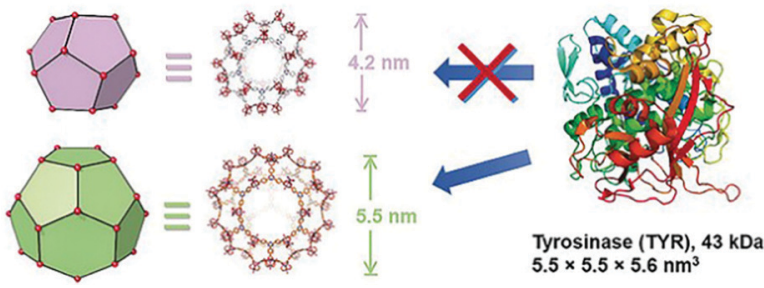

Fig. 5 The structure of NPCN-333 with two kinds of mesoporous cavities. Reprinted with permission. ${ }^{69}$ Copyright 2018 John Wiley and sons.
TYR@PCN-333 and paracetamol was more efficient at inducing cancer cell apoptosis and tumor ablation in vivo than using just paracetamol.

2.1.2 Antigen/antibody@MOFs. The principle of immunotherapy is to stimulate the auto-immune system of humans in order to kill cancer cells. ${ }^{70,71}$ Ovalbumin (OVA) is a common antigen used for antigen-induced immunotherapy. ${ }^{72}$ Zhang et al. developed a pH-responsive Eu-MOF as an antigen delivery system for cancer immunotherapy (Fig. 6). ${ }^{73}$ OVA was encapsulated in situ within the Eu-MOF; then cytosine phosphate guanine $(\mathrm{CpG})$ oligodeoxynucleotide was modified on the surface of the OVA@Eu MOF by Watson-Crick base pairing. The particle size of the composite material was measured to be $\sim 30 \mathrm{~nm}$, and the encapsulation efficiency towards OVA was $\sim 55 \%$. In the acidic environment of the lysosome, the coordination bond between $\mathrm{Eu}^{3+}$ and guanine monophosphate (GMP) became unstable, thereby releasing the OVA antigen. Moreover, $\mathrm{CpG}$, as an immunostimulant, stimulated the activity of cytotoxic T lymphocytes. In vivo experiments indicated that the OVA@Eu MOF/CpG material had a 7-fold enhanced therapeutic effect on B16/OVA tumors with a survival rate of mice close to $100 \%$ when compared to the use of OVA/CpG.

In immunotherapy, aluminum salts are the most common adjuvants because of good biocompatibility and the ability to stimulate immune responses to various antigens. ${ }^{74}$ Sung et al. developed an aluminum-based metal-organic framework (Al-MOF) as an antigen-delivery carrier as well as an adjuvant to effectively induce a durable immune response. ${ }^{75}$ The synthetic strategy was to use aluminum isopropoxide as the metal source, 2-aminoterephthalic acid as the organic ligand and the OVA antigen as the guest molecule, producing the OVA@Al-MOFs under mild ultrasonic conditions. The encapsulation efficiency of the OVA antigen was measured to be $\sim 95 \%$, and the particle size of OVA@Al-MOFs was $\sim 70 \mathrm{~nm}$. In addition, to overcome the mucosal barrier of oral antigens, OVA@Al-MOFs (positively charged) were loaded into yeast-derived capsules (negatively charged) via electrostatic interactions to obtain OVA@Al-MOFs/ YCs composites. In vivo experiments indicated that the OVA@ Al-MOFs/YCs delivery system targeted intestinal $\mathrm{M}$ cells and were subsequently endocytosed by macrophages to accumulate

a)

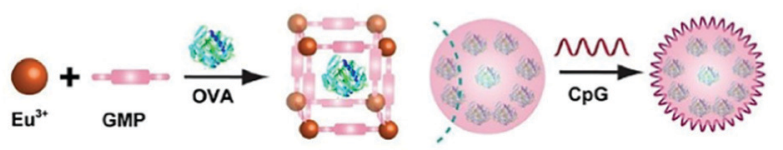

b) tumor microenvironment

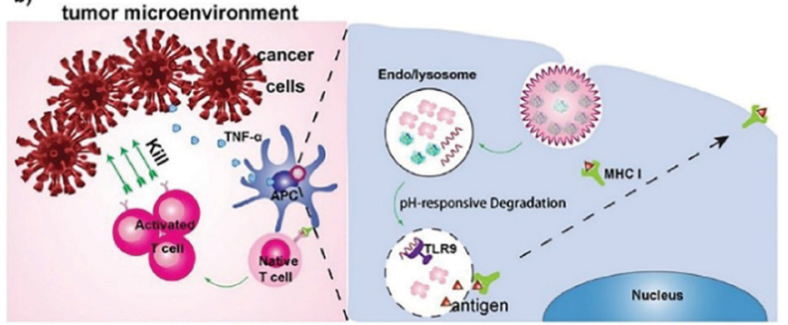

Fig. 6 The construction of the OVA@Eu MOF/CpG material and its antitumor mechanism. Reprinted with permission. ${ }^{73}$ Copyright 2021 Elsevier. 
in mesenteric lymph nodes. In the presence of phosphate ions, Al-MOFs slowly released OVA antigens intracellularly, which induced the continuous production of high levels of mucosal S-IgA and serum IgG antibodies, realizing long-lasting immunotherapy in vivo.

Tumors can evade immune destruction and block antigenactivated immune responses through endogenous "immune checkpoints", ${ }^{76}$ such as the immunosuppressive receptors expressed on $\mathrm{T}$ cells. ${ }^{77}$ As such, the immune response can be restored using immune checkpoint inhibitors (e.g., anti-PD-L1 and anti-PD-1 antibodies). ${ }^{78}$ Antibodies@MOFs based on the host-guest strategy can protect antibodies from being degraded under various environmental conditions. Chen et al. used two zeolitic imidazolate frameworks (ZIF-8 and ZIF-90) as carriers for the immobilization of human immunoglobulin $\mathrm{G}$ ( $\mathrm{IgG})$ polyclonal antibodies (H-IgG) and adalimumab (Ada). ${ }^{79}$ They demonstrated that the encapsulated antibodies exhibited good thermal, chemical and mechanical stability. This study instigated the concept of protecting antibody-based drugs using host-guest chemistry.

Nivolumab (NV) is a monoclonal antibody-based checkpoint inhibitor approved by the U.S. Food and Drug Administration in 2014. ${ }^{80}$ Alsaiari et al. proposed the use of a biomimetic ZIF-8 material as a biocompatible carrier for delivery of NV (Fig. 7). ${ }^{81}$ NV was encapsulated within ZIF-8 by self-assembly to obtain NV@ZIF-8. Then, the cell membrane of MCF-7 cells was coated onto the surface of the NV@ZIF-8 to improve its tumor targeting ability. The average particle size of NV@ZIF-8/CC was determined to be $\sim 166 \mathrm{~nm}$ and the crystal shape was octahedral. Using in vivo experiments, compared with control materials, NV@ZIF-8/ CC significantly improved the activation of $\mathrm{CD}^{+} \mathrm{T}$ cells in hematological malignancies, resulting in higher levels of interferon- $\gamma$ (IFN- $\gamma)$ and tumor necrosis factor- $\alpha$ (TNF- $\alpha$ ) being generated. The lifespan of mice was also significantly prolonged. NV@ZIF-8/CC can specifically recognize tumors, reduce off-target delivery of therapeutic agents reducing side effects

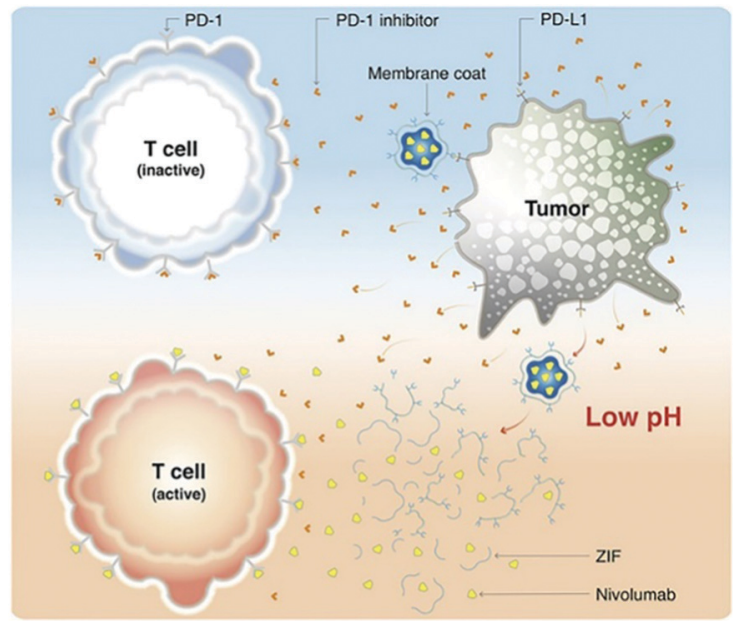

Fig. 7 MOF targeted delivery of NV to activate T cells in a slightly acidic tumor microenvironment. Reprinted with permission. ${ }^{81}$ Copyright 2021 American Association for the Advancement of Science. associated with immunotherapy, improve the sensitivity of the tumor microenvironment to $\mathrm{NV}$, prolong the residence time of NV-ZIF in the tumor, and induce tumor-specific immunity.

2.1.3 Therapeutic proteins@MOFs. In addition to the two types of proteins mentioned above, there are several other therapeutic proteins that are used to treat diseases. ${ }^{82-84}$ For example, cytochrome $c$ (Cyt $c$ ) is a mitochondrial intermembrane protein. When Cyt $c$ is released from mitochondria, a series of biochemical reactions can be initiated, leading to the activation of caspase and cell apoptosis. ${ }^{85}$ Zeng et al. used ZIF-8 to simultaneously encapsulate Cyt $c$ and Chlorin e6 (Ce6) to construct a novel host-guest material with synergistic photodynamic and protein-based therapeutic effects. ${ }^{86}$ Hyaluronic acid (HA) was used to modify the surface of Ce6/Cyt $c @$ @ZIF-8, thus improving the ability to target cancer cells. The encapsulation efficiency of Cyt $c$ by ZIF-8 was determined to be $74.68 \%$, and Cyt $c$ was released in response to the acidic endosomal environment inducing programmed cell death. Interestingly, Cyt $c$ was shown to function under hypoxic conditions and decompose $\mathrm{H}_{2} \mathrm{O}_{2}$ into $\mathrm{O}_{2}$, thereby enhancing the therapeutic efficacy.

The most used medicine for treating diabetes is insulin, and the effective delivery of insulin in vivo is key to controlling the patient's blood sugar levels. ${ }^{87}$ Farha et al. synthesized a zirconium-based porous MOF material denoted as NU-1000 for the encapsulation of insulin with a $40 \mathrm{wt} \%$ loading efficiency. ${ }^{88}$ The MOF "capsule" protected insulin from being degraded by gastric acid and digestive enzymes, and enabled the controlled release of insulin into the bloodstream (Fig. 8). The coordination bonds formed between the zirconium cluster and carboxylic acidbased ligands facilitated the stability of the MOF material at an environmental $\mathrm{pH}$ of 1.5-3.5. Since the size of folded insulin was about $13 \AA \times 34 \AA$, it could be encapsulated by the $34 \AA$ pore of NU-1000. Once the insulin@NU-1000 nanocapsules entered blood circulation, phosphate ions triggered a slow decomposition of NU-1000, thereby enabling the buffered release of insulin. Zhao et al. constructed a glucose-responsive MOF composite as a nano-delivery system for insulin. ${ }^{89}$ The release rate of the system

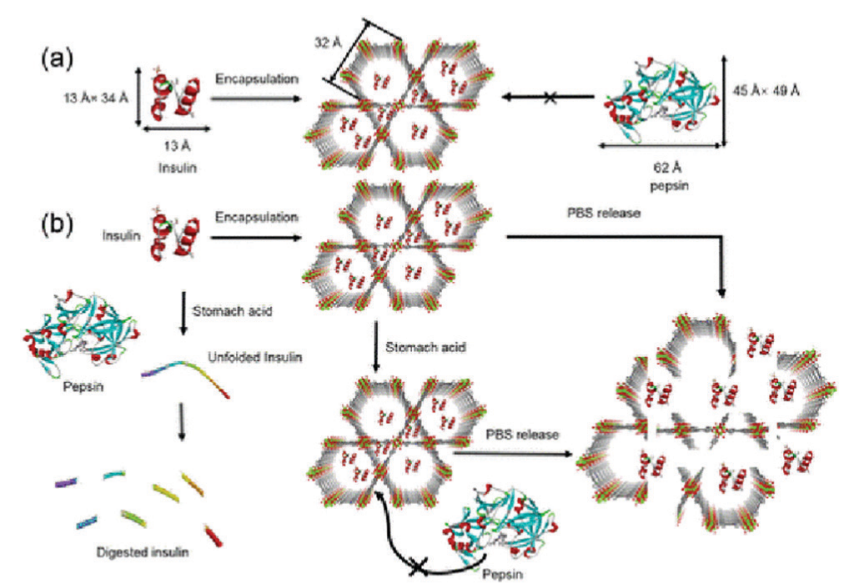

Fig. 8 The pore encapsulation principle and release mechanism of InsulinaNU-1000. Reprinted with permission. ${ }^{88}$ Copyright 2018 American Chemical Society. 
Table 2 The application of Nucleic acid@MOFs in disease treatment ${ }^{a}$

\begin{tabular}{|c|c|c|c|c|c|c|}
\hline Host & Guest & $\begin{array}{l}\text { Size of composite } \\
\text { particle }\end{array}$ & $\begin{array}{l}\text { Release } \\
\text { mechanism }\end{array}$ & Targeted cell lines & Type of disease & Ref. \\
\hline MIL-101 & SiRNA & $170 \pm 10 \mathrm{~nm}$ & Phosphate & MCF-7/T cells & Breast cancer & 94 \\
\hline Zn-NMOF & LNA-antisense miR-224 & $\sim 200 \mathrm{~nm}$ & $\mathrm{pH}$ & HCT116 cells & Colon cancer & 95 \\
\hline ZIF-8 & DNAzymes & $\sim 140 \mathrm{~nm}$ & $\mathrm{pH}$ & T cells, Huh-7 cells & Liver cancer & 97 \\
\hline ZIF-8 & Fe-DNA & $\sim 132 \mathrm{~nm}$ & $\mathrm{pH}$ & 4T1 cells & Breast cancer & 98 \\
\hline ZIF-8 & SiRNA & $\sim 475 \mathrm{~nm}$ & pH & HUVEC cells & Lymphoma & 99 \\
\hline ZIF-C & $\begin{array}{l}\text { siRNAs or CRISPR/ } \\
\text { Cas9 plasmid }\end{array}$ & $\sim 200 \mathrm{~nm}$ & $\mathrm{pH}$ & PC-3 cells & Prostate cancer & 102 \\
\hline ZIF-8 & pDNA & $\sim 275 \mathrm{~nm}$ & $\mathrm{pH}$ & MCF-7 cells & n. a. & 103 \\
\hline
\end{tabular}

was dependent on the concentration of glucose. The host-guest material insulin-GOx@ZIF-8 was prepared by self-assembly. When the blood glucose concentration was high, glucose molecules could enter ZIF-8 and be oxidized by GOx, producing gluconic acid and $\mathrm{H}_{2} \mathrm{O}_{2}$. The ensuing decrease in microenvironmental $\mathrm{pH}$ resulted in decomposition of the MOFs and triggered the release of insulin.

Free hemoglobin $(\mathrm{Hb})$, as a "carrier" of oxygen, exhibits poor stability and short blood circulation. For this reason, $\mathrm{Yu}$ et al. used ZIF-8 as a hard shell to protect $\mathrm{Hb}$, which significantly enhanced its stability under alkaline, oxidative, high-temperature or enzymatic conditions. ${ }^{90}$ The Hb@ZIF-8 material with a particle size of $180 \mathrm{~nm}$ and a zeta potential of $-2.1 \mathrm{mV}$ prolonged the blood circulation time of $\mathrm{Hb}$ and reduced the non-specific distribution in organs. Hb@ZIF-8 was demonstrated to significantly increase the survival time of mice with hemorrhagic shock disease. This study provided an oxygen-carrying platform with good stability and extended circulation time.

\subsection{Therapeutic Nucleic acid@MOFs}

The development of DNAs and RNAs as therapeutic agents has attracted much interest in the field of disease therapy. ${ }^{91}$ Currently, small-interfering RNA (siRNA) and plasmid DNA (pDNA) are the most widely investigated therapeutic agents. However, it has been difficult to effectively deliver these genetic materials to target tissues. These negatively charged biomacromolecules also have difficulty in passing through the cell membrane, which is also negatively charged. In gene therapy, more than $70 \%$ of delivery systems are based on viral vectors, and only $11 \%$ are non-viral vectors. ${ }^{92,93}$ Due to their high loading capacity, ability for controlled drug release and good biodegradability, MOFs have been developed for enhanced delivery of DNAs and RNAs. Table 2 lists the representative and recently developed Nucleic acid@MOFs materials. ${ }^{94-103}$

2.2.1 DNAs@MOFs. Zhou et al. developed four types of isoreticular MOFs (Ni-IRMOF-74-II-V) ${ }^{104}$ As the length of the organic ligands increased, the pore size of the MOF increased from $2.2 \mathrm{~nm}$ to $4.2 \mathrm{~nm}$. The precise encapsulation of singlestranded DNA (ssDNA, 11-53 nt) was achieved by using these MOFs with ssDNA completely filling the pore areas, thereby protecting ssDNAs from degradation. The presence of complementary cDNA sequences in the target cell induced the release of ssDNAs from MOFs without the need for any other external stimuli (Fig. 9). Cellular experiments indicated that the MOFs could effectively deliver DNAzyme (ssDNA with 33 nucleotides) to MCF-7 human breast cancer cells with a transfection efficiency of about $80 \%$ for inhibition of early growth response-1 (EGR-1) gene expression. This research demonstrated that MOFs with properly tuned pore sizes could be used as nonviral vectors for the delivery of ssDNAs to cancer cells.

In addition to pore encapsulation, the in situ encapsulation strategy was also used to construct DNAs@MOFs. Single-stranded DNAzymes are effective for gene silencing. However, due to the lack of DNAzyme cofactors such as special ions, the activity of DNAzymes is insufficient in cells. ${ }^{105}$ To solve this problem, Wang et al. constructed a self-sufficient system by encapsulating a Ce6-modified DNAzyme into ZIF-8 nanoparticles. ${ }^{106}$ ZIF-8 acted

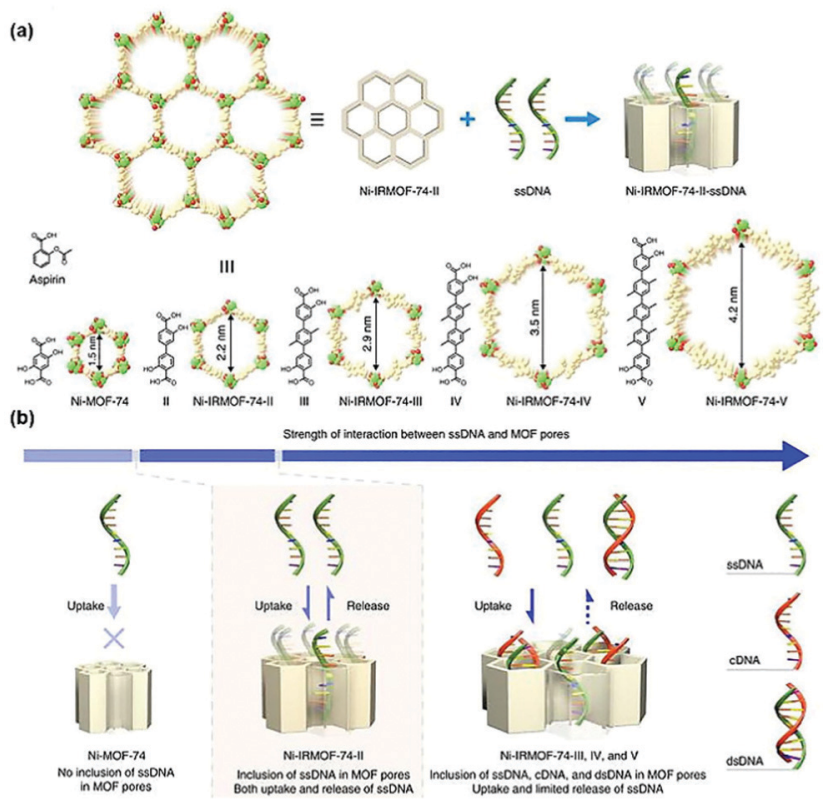

Fig. 9 Precise control of the pore size of the MOF and the encapsulation and release mechanism of ssDNA. Reprinted with permission. ${ }^{104}$ Copyright 2018 Springer Nature. 
as a pH-responsive nanocarrier as well as a supplier of an adequate amount of DNAzyme cofactors (the $\mathrm{Zn}^{2+}$ ions). The particle size of DNAzyme@ZIF-8 was determined to be $167 \mathrm{~nm}$, and the loading capacity for DNAzyme was $10 \mathrm{wt} \%$. The material spontaneously decomposed to release DNAzymes and $\mathrm{Zn}^{2+}$ ions under acidic conditions, and the released species acted as messenger RNA-targeting agents to activate DNAzyme cofactors required for gene therapy. In addition, the auxiliary photosensitizer Ce6 could be used both as a fluorescence imaging agent and in PDT. Similarly, Qu et al. designed a bimetallic MOF material loaded with DNAzymes to develop a host-guest platform for combined chemotherapy and gene therapy. ${ }^{107}$ MCF-7 tumor-bearing mice were intravenously injected with DNAzyme@Cu/ZIF-8. Then, the mice were treated with a prodrug combination (5-azidobenzene-1,3-diol and 4-ethynylphenol) and sodium ascorbate. The $\mathrm{Cu}^{2+}$ ions enriched in the tumor were reduced to $\mathrm{Cu}^{+}$by sodium ascorbate to catalyze the copper-catalyzed azide-alkyne cycloaddition (CuAAC) reaction in situ between 5-azidobenzene-1,3-diol and 4-ethynylphenol, producing a resveratrol derivative toxic to cancer cells. Moreover, the released DNAzymes could be activated by $\mathrm{Zn}^{2+}$, which inhibited the proliferation and metastasis of cancer cells.

DNA plasmids are closed-loop DNA with the ability to selfreplicate for DNA recombination. Shukla et al. used the in situ encapsulation method to encapsulate DNA plasmids into the interior of ZIF-8. ${ }^{108}$ The synthesis was achieved by the addition of the DNA plasmid to an aqueous solution of 2-methylimidazole, followed by the slow addition of an aqueous solution of zinc acetate at room temperature. A green fluorescent protein particle (plGFP) was used as a model genetic macromolecule to validate the transfection efficiency of ZIF-8 materials. Cell transfection experiments indicated that human prostate cancer epithelial cells (PC-3) were transfected with plGFP, and the transfection lasted for up to 4 days.

Ovarian cancer is one of the most malignant gynecological cancers with a high mortality rate. Gene therapy has proven to be an effective way to combat ovarian cancer. As such, Wang et al. constructed a new gene delivery system composed of MIL88A nanoparticles and a microcircular DNA (MC) encoding the anti-CD3/anti-EpCAM bispecific T-cell engager (BiTE). ${ }^{109}$ The expressed products of MC induced $\mathrm{T}$ cell-mediated cytotoxicity to human ovarian cancer cells (SKOV3). The MC@MOF system was shown to have a high gene transfection efficiency in a mouse xenograft model for human peritoneal ovarian cancer. To further improve the transfection efficiency of DNA plasmids, cell-penetrating peptides (CPPs) are good capping systems and provide specific intracellular compartments without macrophage recognition and subsequent phagocytosis, cross the endothelial barrier and enter the cytoplasm of targeted cells. ${ }^{110}$

Langel et al. modified CPPs on the surface of ZIF-8 by electrostatic adsorption to improve the transfection efficiency of the plasmid (pGL3). HeLa cells were transfected with pGL3@ ZIF-8/CPPs and pGL3@ZIF-8, respectively, and the results indicated that ZIF-8/CPPs increased the transfection efficiency of pGL3 by 5 -fold. ${ }^{111}$ Conventional gene therapy relies on the introduction of therapeutically effective DNA fragments into target cells to correct disease-related genes. In contrast, Leong et al. developed a nanoparticle that can clear circulating free DNA (cfDNA) for the treatment of sepsis. ${ }^{112}$ The cationic metal-organic "nanotrap" (PEI-g-ZIF) was prepared in one pot to encapsulate cfDNA (Fig. 10). The particle size of PEI- $g$-ZIF was determined to be $100 \mathrm{~nm}$. The PEI- $g$-ZIF captured cfDNA through electrostatic interactions, thereby suppressing cfDNA-induced activation of toll-like receptor (TLR) and the release of inflammatory cytokines. The biological evaluation indicated that PEI- $g$-ZIF NPs, as "nano traps", exhibited good therapeutic efficiency for the clearance of cfDNA. The host-guest material effectively reduced inflammation and reversed the progress of sepsis.

2.2.2 RNAs@MOFs. RNA interference (RNAi) is a naturally occurring gene down-regulation mechanism that has been widely used as a tool for biological research. ${ }^{113}$ MicroRNA (miRNA), a small endogenous non-coding RNA, is a promising class of nucleic acid-based therapeutics. miRNAs can simultaneously regulate a wide range of target genes for tumor inhibition. ${ }^{114,115}$ Yang et al. used ZIF-8 as a delivery system achieving the effective delivery of miRNA into cells. ${ }^{116}$ As a gene carrier and chemodynamic therapeutic inducer, ZIF-8 exhibited a high loading capacity for miRNA (miR-34a-m) of B-cell lymphoma-2 (Bcl-2). Once internalized by cells, the ZIF-8 was decomposed to release the miRNA into the cytoplasm, leading to a significant decrease in the expression of Bcl-2 at both the mRNA and protein levels, resulting in enhanced cancer cell apoptosis. Interestingly, $\mathrm{Zn}^{2+}$ could induce the production of ROS to further promote tumor cell apoptosis. The combined genetic/chemodynamic therapy enabled by the miR-34a-m@ZIF-8 host-guest material effectively inhibited tumor growth in a triple-negative breast cancer mouse model.

siRNAs are short double-stranded RNA molecules that can be designed and synthesized for use in the RNAi pathway. siRNAs have evolved as an important tool for identifying the
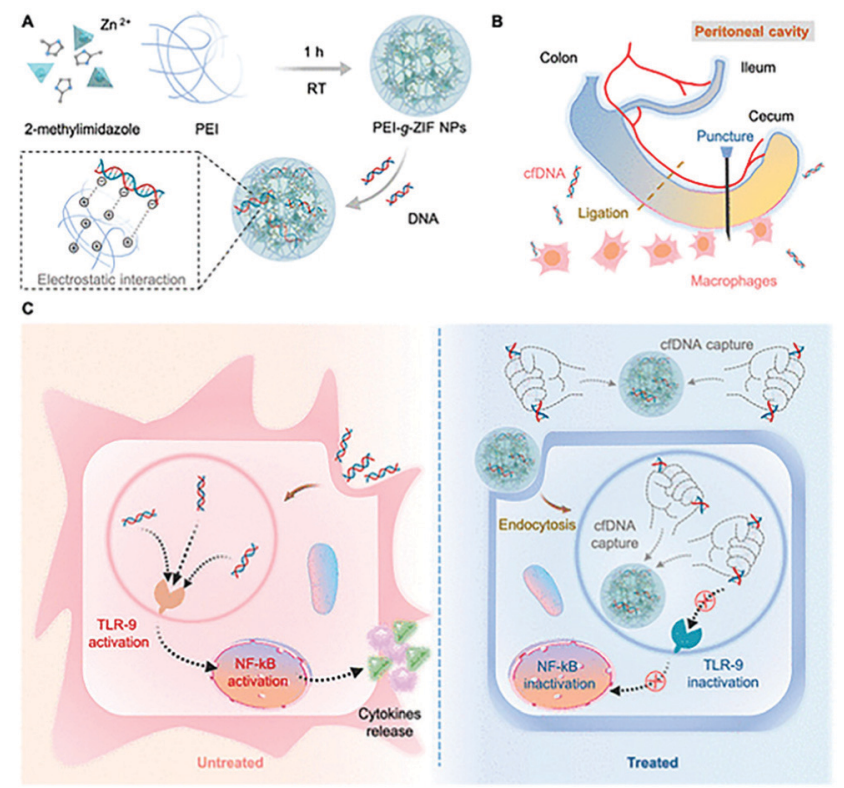

Fig. 10 Schematic illustration of the preparation of PEI-g-ZIF and its capture of cfDNA. Reprinted with permission. ${ }^{112}$ Copyright 2021 American Chemical Society. 
function of genes and are widely used in the treatment of human diseases. ${ }^{117}$ In 2014, Lin et al. developed a nanoscale MOF material (siRNA@University of Oslo/Cisplatin [UiO-Cis]) to deliver a combination of MDR gene-silencing siRNAs (Bcl-2, P-glycoprotein, and survivin) to cancer cells. The presence of the UiO-Cis host material facilitated the escape of the siRNAs from endosomes intracellularly to silence MDR genes in drug-resistant ovarian cancer cells. The host-guest composite reduced the expression of the three target proteins by $50 \%$. $^{118}$

Jimenez et al. used NU-1000 nanoparticles to enhance the delivery of siRNA. NU-1000 has a hexagonal mesoporous channel with a pore size of $3 \mathrm{~nm}$, which is suitable for loading siRNAs. ${ }^{119}$ Computational simulations indicated that the binding energy of nNU-1000 with siRNA was $-878 \mathrm{~kJ} \mathrm{~mol}^{-1}$. In addition, the siRNA@MOFs host-guest material was combined with various cofactors (proton sponge, $\mathrm{KALA}$ peptide and $\mathrm{NH}_{4} \mathrm{Cl}$ ) to diminish endosomal retention and thus increase the gene-knockout efficiency.

Zhang et al. constructed a biomimetic nanoparticle for targeted delivery of siRNA in vivo (Fig. 11). ${ }^{120}$ First, the siRNA was loaded into the interior of the ZIF-8 through a one-pot method, and then the surface of the material was coated with a naturally derived platelet membrane. In vitro experiments indicated that the P-MOF-siRNA materials coated with platelet membranes had the capacity for tumor targeting, achieving efficient gene silencing of multiple target genes. The host-guest system also exhibited a good therapeutic effect in tumor-bearing breast cancer mice models. Similarly, Zhang et al. used HeLa cell membranes $\left(\mathrm{CM}_{\mathrm{HeLa}}\right)$ to camouflage ZIF-8 for targeted delivery of siRNA inhibiting the Polo-like kinase 1 (PLK1) gene of lung cancer cells. ${ }^{121}$

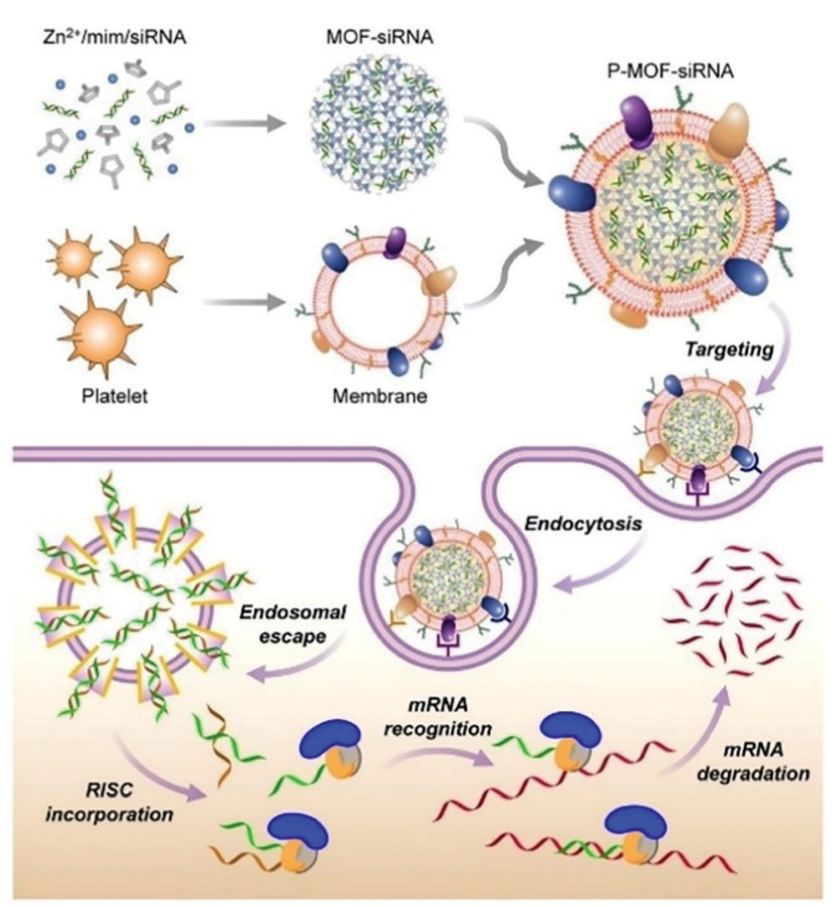

Fig. 11 The construction of P-MOF-siRNA and its application in gene silencing. Reprinted with permission. ${ }^{120}$ Copyright 2020 American Association for the Advancement of Science.
PLK1 belongs to a highly conserved protein family, PLKs, which regulate the cell cycle through different signaling pathways including triggering cell mitosis, facilitating spindle assembly and promoting centrosome maturation. ${ }^{122}$ siRNA@ZIF-8/CM $\mathrm{M}_{\mathrm{HeLa}}$ resulted in a $72 \%$ reduction of PlK1 expression in tumor-bearing models. In contrast, siRNA alone exhibited a minimal effect on PLK1 suppression. This MOF biomimetic delivery system exhibited enhanced synergistic effects of homotopic targeting and gene silencing.

siSOX9 is a siRNA that down-regulates the expression of SOX9, which is an important transcription factor for glial cells. Qu et al. designed a cerium dioxide-doped MIL-100 material as a carrier to deliver siSOX9 and retinoic acid (RA) to neural stem cells (NSC). ${ }^{123}$ MIL-100 is a $\mathrm{H}_{2} \mathrm{O}_{2}$-responsive material that can release siSOX9 and RA in the lesion area, thereby modulating the differentiation of NSC into neurons. Furthermore, cerium dioxide acted as an antioxidant nanoenzyme that protected newborn neurons from oxidative damage in an inflammatory environment, thus enabling a longer survival rate of newborn neurons. The MIL-100 host-guest material systems exhibited excellent drug loading efficiency and promoted the directed differentiation of neural stem cells, improving the cognitive function in a triple-transgenic mouse model of Alzheimer's disease.

\subsection{Host-guest materials of other Biomacromolecules@MOFs}

In recent years, peptide-based therapeutics have played an important role in the treatment of diseases. Compared to therapeutic proteins, peptides can be more easily produced at a lower cost. However, peptides can also be easily degraded in vivo. ${ }^{124}$ Liang et al. synthesized a ZIF-8 material to encapsulate a therapeutic peptide (peptide 46), which can upregulate the expression of the tumor suppressor gene p53 in cancer cells. ${ }^{125}$ The hydrophobic cavities in ZIF-8 effectively eliminated polar solvents to prevent hydrolysis of peptides. The resulting Peptide 46@ZIF-8 significantly inhibited the proliferation of MCF-7 cells. Similarly, Liu et al. used ZIF-8 materials to encapsulate melittin in situ (Fig. 12). ${ }^{126}$ Melittin (MLT) is an amphiphilic cationic

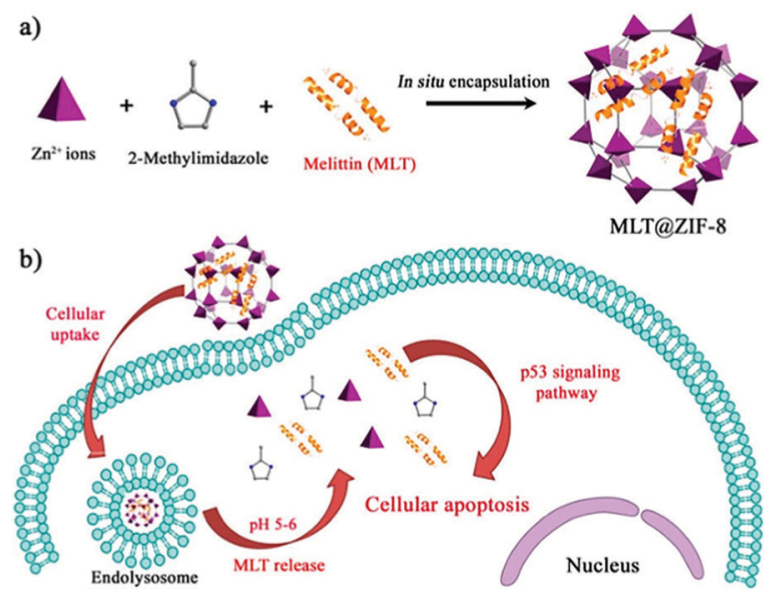

Fig. 12 Preparation of MLTaZIF-8 NPs and its application in anti-cancer therapy. Reprinted with permission. ${ }^{126}$ Copyright 2018 American Chemical Society. 
peptide, which can insert into the cell membrane producing transmembrane "holes" that lead to cell apoptosis. When melittin is delivered into cells, it interacts with the membrane of subcellular organelles to activate transcriptional regulation. In a series of transcriptome analyses, it was shown that MLT@ZIF-8 could regulate the expression of 3383 genes. For example, the phosphoinositide 3-kinase/serine-threonine kinase-regulated p53 pathway was activated in MLT@ZIF-8 treated A549 cells. This research represents the first example where the anti-cancer mechanism of MLT@ZIF-8 through transcriptomics analysis was elucidated.

Osteogenic growth peptide (OGP) has been widely used to improve the proliferation and differentiation of osteoblastrelated cells. ${ }^{127}$ Chen et al. prepared OGP@ZIF-67 nanoparticles using an in situ encapsulation approach and then deposited OGP@ZIF-67 onto the surface of titanium dioxide nanotubes (TNTs) using a cathodic electrophoretic deposition method to obtain TNT-ZIF-67@OGP. ${ }^{128}$ The composite material enhanced the proliferation and differentiation of mesenchymal stromal cells (MSCs) whilst inhibiting the inflammatory response of M1 macrophages. Using an infected femur animal model, TNTZIF-67@OGP materials exhibited excellent anti-inflammatory effects at the early stage of implantation and enhanced osseointegration of the bone-implant at a later stage. A comparison of the osseointegration capacities of TNT and TNT-ZIF-67@OGP in vivo indicated that the new-bone formation capacity around TNT-ZIF-67@OGP was 2-fold higher than that of TNT.

Positively charged peptides, such as the dodechistidine peptide (H12), can enhance the cellular uptake of MOF materials and/or facilitate their transport across cell membranes. Tang et al. prepared a 5-carboxyfluorescein (FAM)-labeled H12 (fH12)@ZIF-8 material as an efficient $\mathrm{pH}$-responsive delivery system. ${ }^{129}$ Human hepatocellular carcinoma cells (HepG2) were incubated with 5-FAM/ZIF-8 (without the peptide) or fH12/ZIF-8 for 2 hours. The fluorescence of fH12/ZIF-8 was determined to be much stronger than that of 5-FAM/ZIF-8, suggesting that the cellular uptake of ZIF-8 was enhanced by doping with H12.

Polysaccharides play important functional roles in the biological system, and polysaccharide-based therapeutic agents have been increasingly developed. ${ }^{130}$ In order to achieve effective encapsulation and controllable release of polysaccharides, Falcaro et al. proposed the use of ZIF-8 encapsulated polysaccharides in situ. ${ }^{131}$ The authors demonstrated that an increase in the number of carboxyl groups in the polysaccharide structure led to a more effective coordination with metal cations, thus facilitating the self-assembly process of the host-guest materials. Hyaluronic acid (HA) is a therapeutic agent used for the treatment of osteoarthritis (OA). HA reduces inflammation in OA patients, protects chondrocytes from free-radical damage, and promotes cartilage regeneration. ${ }^{132}$ Kai et al. used MIL-100 (Fe) to simultaneously load HA and an anti-inflammatory protocatechuic acid (PCA) to obtain the MIL-100@HA@PCA composite for the treatment of OA. ${ }^{133}$ MIL-100@HA@PCA released HA and PCA slowly under acidic conditions, thereby reducing synovial inflammation in OA joints. Falcaro et al. used three types of pH-responsive MOF materials (ZIF-8, ZIF-90 and MAF-7) for the

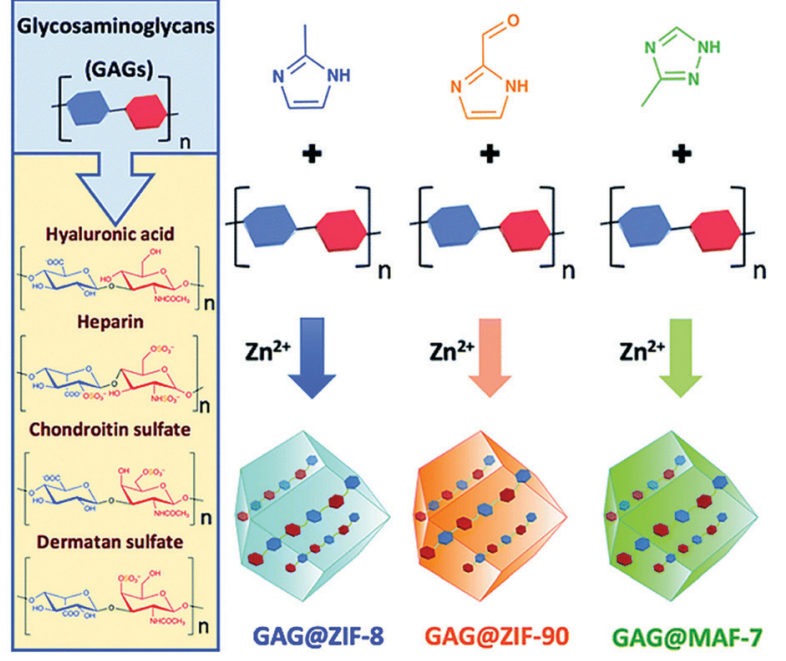

Fig. 13 The construction of three types of pH-responsive GAGaMOF materials. Reprinted with permission. ${ }^{134}$ Copyright 2020 The Royal Society of Chemistry.

in situ encapsulation of a variety of glycosaminoglycans (GAG) for disease treatment (Fig. 13). ${ }^{134}$

The GAG family consists of hyaluronic acids, chondroitin sulfates, dermatan sulfates, keratin sulfates and heparan sulfates. GAGs play an important role in modulating cell development, repair, and replacement. For example, GAGs containing chondroitin sulfates are indispensable for the development of the brain, cartilage, and other tissues, and for maintaining the stability of neuronal synapses. Heparan sulfates are involved in the development of cells and angiogenesis, and in the regulation of blood clotting properties. GAGs are therefore important commercial therapeutics used for the treatment of human diseases including osteoarthritis, thrombosis, inflammation, and wound healing. The above strategy was successful in loading clinically approved GAG therapeutics (heparin, hyaluronic acid, chondroitin sulfate, dermatan sulfate, GM-1111, and HepSYL proteoglycan) into the MOF. Different GAG@MOF materials displayed varied loading efficiencies, guest space distribution and release dynamics. For example, GAG@ZIF-8 or GAG@MAF-7 host-guest materials were the best choices for treating osteomyelitis and infected wounds since they exhibited rapid release. However, GAG@ZIF-90 was the material of choice for controlling the drug release rate and reducing side effects. This research was the first to prepare GAGs@MOFs composites with tunable functions (e.g., encapsulation efficiency, protection mechanism, drug release rate).

The resistance of bacteria to antibiotics continues to increase, and to date it has been difficult to develop targeted vaccines for pathogenic bacteria. The difficulty mainly lies in the choice of suitable bacterial antigens for eliciting immune responses. Gassensmith et al. have used the in situ encapsulation method to load uropathogenic Escherichia coli (UPEC) to ZIF-8. The host-guest assembly was achieved through the weak interaction between $\mathrm{Zn}^{2+}$ and the peptide backbones on the membrane of the bacteria. ${ }^{135}$ The self-assembly did not change the conformation of proteins and saccharides on the membrane surface. However, the 
bacteria were deactivated. The protective layer of ZIF-8 was decomposed in vivo, and the re-exposed proteins and oligosaccharides were released to trigger immune responses. The UPEC@ZIF-8 host-guest material significantly increased the concentration of $\operatorname{lgG}$ in the serum, induced a strong humoral response, and prolonged the survival time of mice infected with fatal sepsis.

\section{Conclusions and outlook}

As an emerging class of delivery systems, MOFs have contributed substantially to the enhanced delivery of therapeutic biomacromolecules. Based on structurally well-defined pore networks and the mild host-guest chemistry used in their construction, different types of biomacromolecules (including antigens/antibodies, enzymes, therapeutic proteins, nucleic acids, polypeptides and polysaccharides) are efficiently encapsulated in a variety of nanoscale MOFs and exhibit sufficient retained bioactivity upon reaching the targeted cells. The two most popular host-guest strategies to construct Biomacromolecules@MOFs are the pore encapsulation and in situ encapsulation strategy. The internal/external stimuli in cells that activate the biomacromolecular release from MOFs include $\mathrm{pH}$, ions, competitive binding agents, and redoxactive species. In addition, by combining therapeutic biomolecules with other therapeutic agents and/or adjuvants, multimodal disease therapy has been achieved in vivo.

Although significant progress has been made in the development of Biomacromolecules@MOFs host-guest delivery systems for disease treatment, several challenges remain that hamper the transformation of this emerging technique into clinical practice.

(1) Potential side effects and biosafety of the MOF delivery system should be systematically studied. These are important factors that determine whether MOFs can enter clinical trials. In the process of constructing MOFs, low-toxicity organic ligands and metal ions should be selected, and the tolerance of these materials by the human body should be considered. How each MOF is degraded and distributed in the human body should be carefully assessed by standard pharmacological and pharmacokinetic assays.

(2) Currently, only a limited number of MOF materials have been used for enhanced delivery of biomacromolecules. Structurally more diverse MOF systems for biomacromolecules with exquisitely tunable porous structure, chemical structure and morphology need to be developed. In particular, the size of Biomacromolecules@ MOFs needs to be finely controlled to achieve good internal circulation in vivo. Another question is how to ensure the structural uniformity and repeatability of MOF materials when they are synthesized in bulk. In addition, to overcome the relatively harsh synthetic conditions of MOFs materials (e.g., high temperature, high pressure and the use of organic solvents), recently, a novel and generalizable approach to the encapsulation of small-molecule drugs in MOFs, known as the mechanochemical "SMART" strategy, has been developed. ${ }^{136-138}$ This method just requires a single mechanochemical process for drug loading, minimizing the harsh conditions required for the traditional solvothermal MOFs syntheses. We envision that the mechanochemical strategy can be used for Biomacromolecules@MOFs to help retain the structural and functional integrity of biomacromolecular therapeutics of interest.

(3) The mechanisms by which biomacromolecules bind MOFs remain largely unexplained. In-depth mechanistic studies can offer an important theoretical basis for the efficiencyenhanced loading and release of therapeutic biomacromolecules.

(4) The targeting specificity of MOF materials still needs to be improved using the surface functionalization of MOFs with appropriate targeting molecules, thereby improving the accumulation of the therapeutic agents at the targeted cells (reducing offtargeting).

(5) Due to the complexity and diversity of most human diseases, it is necessary to develop multifunctional Biomacromolecules@ MOFs to achieve multi-target and multi-modal treatment of diseases. Significantly, the therapeutic results obtained in animal-based disease models may differ from those in humans. To enable clinical practice, several pre-clinical evaluations are required.

In conclusion, we anticipate that, once the problems outlined above have been addressed, Biomacromolecules@MOFs delivery systems will become one of the most promising materials for biomedical applications. Although big challenges remain, the rapid development of MOFs due to advancements in chemistry, materials science, and biotechnology will result in Biomacromolecules@MOFs suitable for the clinical translation of MOF material-based therapeutics in the near future.

\section{Conflicts of interest}

There are no conflicts to declare.

\section{Acknowledgements}

The authors thank the National Natural Science Foundation of China (No. 21788102, 91853201), the Shanghai Municipal Science and Technology Major Project (2018SHZDZX03) and the international cooperation program of Shanghai Science and Technology Committee (17520750100). T. D. J. wishes to thank the Royal Society for a Wolfson Research Merit Award and the Open Research Fund of the School of Chemistry and Chemical Engineering, Henan Normal University for support (2020ZD01).

\section{Notes and references}

1 H. J. Kong and D. J. Mooney, Nat. Rev. Drug Discovery, 2007, 6, $455-463$.

2 X. Liu, F. Wu, Y. Ji and L. Yin, Bioconjugate Chem., 2018, 30, 305-324.

3 S. Iqbal, M. Blenner, A. Alexander-Bryant and J. Larsen, Biomacromolecules, 2020, 21, 1327-1350.

4 H. Yin, R. L. Kanasty, A. A. Eltoukhy, A. J. Vegas, J. R. Dorkin and D. G. Anderson, Nat. Rev. Genet., 2014, 15, 541-555.

5 A. Gigante, M. Li, S. Junghänel, C. Hirschhäuser, S. Knauer and C. Schmuck, MedChemComm, 2019, 10, 1692-1718.

6 A. Pachioni-Vasconcelos Jde, A. M. Lopes, A. C. Apolinário, J. K. Valenzuela-Oses, J. K. Valenzuela-Oses, J. S. Costa, O. Nascimento Lde, A. Pessoa, L. R. Barbosa and O. Rangel-Yagui Cde, Biomater. Sci., 2016, 4, 205-218.

7 S. Deodhar and A. K. Dash, Ther. Delivery, 2018, 9, 857-872. 
8 Q. L. Zhu and Q. Xu, Chem. Soc. Rev., 2014, 43, 5468-5512.

9 S. Wang, C. M. McGuirk, A. d'Aquino, J. A. Mason and C. A. Mirkin, Adv. Mater., 2018, 30, 1800202.

10 H. Cai, Y. L. Huang and D. Li, Coord. Chem. Rev., 2019, 378, 207-221. 11 H. Sun, Y. Li, S. Yu and J. Liu, Nano Today, 2020, 35, 100985.

12 J. Zhou, G. Yu and F. Huang, Chem. Soc. Rev., 2017, 46, 7021-7053.

13 C. Y. Sun, C. Qin, X. L. Wang and Z. M. Su, Expert Opin. Drug Delivery, 2013, 10, 89-101.

14 M. P. Auuçafy, B. L. da Silva, J. A. Oshiro-Junior, E. B. Manaia, B. G. Chiari-Andréo, R. A. M. Armando, R. C. G. Frem and L. A. Chiavacci, Curr. Pharm. Des., 2020, 26, 4174-4184.

15 M. X. Wu and Y. W. Yang, Adv. Mater., 2017, 29, 1606134.

16 D. Liu, B. Bai, Y. Sun and Y. Guo, Mater. Express, 2020, 10, 1197-1203.

17 H. Zhang, J. Zhang, Q. Li, A. Song, H. Tian, J. Wang, Z. Li and Y. Luan, Biomaterials, 2020, 245, 119983.

18 D. E. Al-Ansari, N. A. Mohamed, I. Marei, A. Zekri, Y. Kameno, R. P. Davies, P. D. Lickiss, M. M. Rahman and H. Abou-Saleh, Nanomaterials, 2020, 10, 1028.

19 B. M. Jarai, Z. Stillman, L. Attia, G. E. Decker, E. D. Bloch and C. A. Fromen, ACS Appl. Mater. Interfaces, 2020, 12, 38989-39004.

20 S. F. Li, H. Guo, Y. Huang, C. M. Li, Y. Liu and J. Han, J. Polym. Res., 2020, 27, 1-11.

21 Y. Sakamaki, J. Ozdemir, Z. Heidrick, A. Azzun, O. Watson, M. Tsuji, C. Salmon, A. Sinha, J. Batta-Mpouma, Z. McConnell, D. Fugitt, Y. Du, J. W. Kim and H. Beyzavi, ACS Appl. Bio Mater., 2021, 4, 1432-1440.

22 B. Silver, K. Ramaiya, S. B. Andrew, O. Fredrick, S. Bajaj, S. Kalra, B. M. Charlotte, K. Claudine and A. Makhoba, Diabetes Ther., 2018, 9, 449-492.

23 M. B. Parmar, R. B. Kc, R. Lobenberg and H. Uludağ, Biomacromolecules, 2018, 19, 4193-4206.

24 X. Li, W. Yang, Y. Zou, F. Meng, C. Deng and Z. Zhong, J. Controlled Release, 2015, 220, 704-714.

25 T. Wan and Y. Ping, Adv. Drug Delivery Rev., 2021, 168, 196-216.

26 P. Yang, C. Lu, W. Qin, M. Chen, G. Quan, H. Liu, L. Wang, X. Bai, X. Pan and C. Wu, Acta Biomater., 2020, 104, 147-157.

27 H. He, Q. Liang, M. C. Shin, K. Lee, J. Gong, J. Ye, Q. Liu, J. Wang and V. Yang, Front. Chem. Sci. Eng., 2013, 7, 496-507.

28 B. Leader, Q. J. Baca, D. E. Golan and D. E. Golan, Nat. Rev. Drug Discovery, 2008, 7, 21-39.

29 C. Chu, M. Su, J. Zhu, D. Li, H. Cheng, X. Chen and G. Liu, Theranostics, 2019, 9, 3134

30 X. Lian, A. Erazo-Oliveras, J. P. Pellois and H. C. Zhou, Nat. Commun., 2017, 8, 1-10.

31 H. Y. Guan, R. J. LeBlanc, S. Y. Xie and Y. Yue, Coord. Chem. Rev., 2018, 369, 76-90.

32 D. Liu, D. Zou, H. Zhu and J. Zhang, Small, 2018, 14, 1801454.

33 K. Liang, R. Ricco, C. M. Doherty, M. J. Styles, S. Bell, N. Kirby, S. Mudie, D. Haylock, A. J. Hill, C. J. Doonan and P. Falcaro, Nat. Commun., 2015, 6, 1-8.

34 G. Chen, S. Huang, X. Kou, F. Zhu and G. Ouyang, Angew. Chem., 2020, 132, 14051-14058.

35 F. Carraro, J. D. Williams, M. Linares-Moreau, C. Parise, W. Liang, H. Amenitsch, C. Doonan, C. O. Kappe and P. Falcaro, Angew. Chem., 2020, 132, 8200-8204.

36 Y. Pan, Y. Liu, G. Zeng, L. Zhao and Z. Lai, Chem. Commun., 2011, 47, 2071-2073.

37 F. K. Shieh, S. C. Wang, S. Y. Leo and K. W. Wu, Chem. - Eur. J., 2013, 19, 11139-11142.

38 C. G. Jones, V. Stavila, M. A. Conroy, P. Feng, B. V. Slaughter, C. E. Ashley and M. D. Allendorf, ACS Appl. Mater. Interfaces, 2016, 8, 7623-7630.

39 M. Wei, Y. Wan and X. Zhang, J. Compos. Sci., 2021, 5, 101.

$40 \mathrm{H}$. D. Lawson, S. P. Walton and C. Chan, ACS Appl. Mater. Interfaces, 2021, 13, 7004-7020.

41 C. Wang, G. Sudlow, Z. Wang, S. Cao, Q. Jiang, A. Neiner, J. J. Morrissey, E. D. Kharasch, S. Achilefu and S. Singamaneni, Adv. Healthcare Mater., 2018, 7, 1800950.

42 J. Bai, C. Peng, L. Guo and M. Zhou, ACS Biomater. Sci. Eng., 2019, 5, 6207-6215.

43 X. Wan, L. Song, W. Pan, H. Zhong, N. Li and B. Tang, ACS Nano, 2020, 14, 11017-11028.

44 X. Yang, Q. Tang, Y. Jiang, M. Zhang, M. Wang and L. Mao, J. Am. Chem. Soc., 2019, 141, 3782-3786.
45 J. Jia, S. Zhang, K. Wen and Q. Li, Int. J. Nanomed., 2019, 14, 9971. 46 J. Yang, S. Ma, R. Xu, Y. Wei, J. Zhang, T. Zou, Z. Wang, H. Deng, N. Yang and Q. Shen, J. Controlled Release, 2021, 334, 21-33.

47 C. Zhang, L. Zhang, W. Wu, F. Gao, R. Q. Li, W. Song, Z. N. Zhuang, C. J. Liu and X. Z. Zhang, Adv. Mater., 2019, 31, 1901179.

48 J. Zhang, M. He, C. Nie, M. He, Q. Pan, C. Liu, Y. Hu, T. Chen and X. Chu, Chem. Sci., 2020, 11, 7092-7101.

49 Y. Qi, L. Wang, H. Guo, Y. Pan, Z. Xie, N. Jin and Y. Huang, Biomater. Sci., 2019, 7, 4022-4026.

50 S. K. Alsaiari, S. Patil, M. Alyami, K. Alamoudi, F. Aleisa, J. Merzaban, M. Li and N. M. Khashab, J. Am. Chem. Soc., 2018, 140, 143-146.

51 S. Wang, Y. Chen, S. Wang, P. Li, C. A. Mirkin and O. K. Farha, J. Am. Chem. Soc., 2019, 141, 2215-2219.

52 W. Xie, T. L. Yin, Y. L. Chen, D. M. Zhu, M. H. Zan, B. Chen, L. W. Ji, L. Chen, S. S. Guo, H. M. Huang, X. Z. Zhao, Y. Wang, Y. Wu and W. Liu, Nanoscale, 2019, 11, 8293-8303.

53 X. X. Yang, P. Feng, J. Cao, W. Liu and Y. Tang, ACS Appl. Mater. Interfaces, 2020, 12, 13613-13621.

54 S. Datta, K. N. Rajnish, C. George Priya Doss, S. Melvin Samuel, E. Selvarajan and H. Zayed, Expert Opin. Biol. Ther., 2020, 20, 1151-1174.

55 S. A. Farhadi, E. Bracho-Sanchez, S. L. Freeman, B. G. Keselowsky and G. A. Hudalla, Bioconjugate Chem., 2017, 29, 649-656.

56 H. A. D. Lagassé, A. Alexaki, V. L. Simhadri, N. H. Katagiri, W. Jankowski, Z. E. Sauna and C. Kimchi-Sarfaty, F1000Research, 2017, 6, 113.

57 V. Lykourinou, Y. Chen, X. S. Wang, L. Meng, T. Hoang, L. J. Ming, R. L. Musselman and S. Ma, J. Am. Chem. Soc., 2011, 133, 10382-10385.

58 Y. Chen, V. Lykourinou, C. Vetromile, T. Hoang, L. J. Ming, R. W. Larsen and S. Ma, J. Am. Chem. Soc., 2012, 134, 13188-13191.

59 P. Li, Q. Chen, T. C. Wang, N. A. Vermeulen, B. L. Mehdi, A. Dohnalkova, N. D. Browning, D. Shen, R. Anderson, D. A. GómezGualdrón, F. M. Cetin, J. Jagiello, A. M. Asiri, J. F. Stoddart and O. K. Farha, Chem, 2018, 4, 1022-1034.

60 T. T. Chen, J. T. Yi, Y. Y. Zhao and X. Chu, J. Am. Chem. Soc., 2018, 140, 9912-9920.

61 J. A. Lopez, O. Susanto, M. R. Jenkins, N. Lukoyanova, V. R. Sutton, R. H. Law, A. Johnston, C. H. Bird, P. I. Bird, J. C. Whisstock, J. A. Trapani, H. R. Saibil and I. Voskoboinik, Blood, 2013, 121, 2659.

62 Q. Zhao, Z. Gong, Z. Li, J. Wang, J. Zhang, Z. Zhao, P. Zhang, S. Zheng, R. J. Miron, Q. Yuan and Y. Zhang, Adv. Mater., 2021, 33, 2100616.

63 M. Xuan, J. Shao and J. Li, Natl. Sci. Rev., 2019, 6, 551-561.

64 W. Liu, Q. Yan, C. Xia, X. Wang, A. Kumar, Y. Wang, Y. Liu, Y. Pan and J. Liu, J. Mater. Chem. B, 2021, 9, 4459-4474.

65 G. Cheng, W. Li, L. Ha, X. Han, S. Hao, Y. Wan, Z. Wang, F. Dong, X. Zou, Y. Mao and S. Y. Zheng, J. Am. Chem. Soc., 2018, 140, $7282-7291$.

66 M. Z. Alyami, S. K. Alsaiari, Y. Li, S. S. Qutub, F. A. Aleisa, R. Sougrat, J. S. Merzaban and N. M. Khashab, J. Am. Chem. Soc., 2020, 142, 1715-1720.

67 Y. Nivoix, D. Levêque, R. Herbrecht, J. C. Koffel, L. Beretz and G. Ubeaud-Sequier, Clin. Pharmacokinet., 2008, 47, 779-792.

68 G. K. Meghwanshi, N. Kaur, S. Verma, N. K. Dabi, A. Vashishtha, P. D. Charan, P. Purohit, H. S. Bhandari, N. Bhojak and R. Kumar, Biotechnol. Appl. Biochem., 2020, 67, 586-601.

69 X. Lian, Y. Huang, Y. Zhu, Y. Fang, R. Zhao, E. Joseph, J. Li, J. P. Pellois and H. C. Zhou, Angew. Chem., 2018, 130, 5827-5832.

70 R. S. Riley, C. H. June, R. Langer and M. J. Mitchell, Nat. Rev. Drug Discovery, 2019, 18, 175-196.

71 Y. R. Murciano-Goroff, A. B. Warner and J. D. Wolchok, Cell Res., 2020, 30, 507-519.

72 N. Habibi, S. Christau, L. J. Ochyl, Z. Fan, A. H. Najafabadi, M. Kuehnhammer, M. Zhang, M. Helgeson, R. V. Klitzing, J. J. Moon, J. L. Moon and J. Lahann, Adv. Ther., 2020, 3, 2000100.

73 F. Duan, X. Feng, X. Yang, W. Sun, Y. Jin, H. Liu, K. Ge, Z. Li and J. Zhang, Biomaterials, 2017, 122, 23-33.

74 E. Jensen-Jarolim, World Allergy Organ., 2015, 8, 7.

75 Y. B. Miao, W. Y. Pan, K. H. Chen, H. J. Wei, F. L. Mi, M. Y. Lu, Y. Chang and H. W. Sung, Adv. Funct. Mater., 2019, 29, 1904828.

76 S. M. Toor, V. S. Nair, J. Decock and E. Elkord, Semin. Cancer Biol., $2020,65,1-12$.

77 H. R. Kim, H. J. Park, J. Son, J. G. Lee, K. Y. Chung, N. H. Cho, H. S. Shim, S. Park, G. Kim, H. I. Yoon, H. G. Kim, Y. W. Jung, 
B. C. Cho, S. Y. Park, S. Y. Rha and S. J. Ha, J. Immunother. Cancer, 2019, 7, 1-13.

78 L. S. Wood, N. P. Moldawer and M. S. N. Colleen Lewis, Clin. J. Oncol. Nurs., 2019, 23, 271-280.

79 Y. Feng, H. Wang, S. Zhang, Y. Zhao, J. Gao, Y. Zheng, P. Zhao, Z. Zhang, M. J. Zaworotko, P. Cheng, S. Ma and Y. Chen, Adv. Mater., 2019, 31, 1805148.

80 F. Finkelmeier, O. Waidmann and J. Trojan, Expert Rev. Anticancer Ther., 2018, 18, 1169-1175.

81 S. K. Alsaiari, S. S. Qutub, S. Sun, W. Baslyman, M. Aldehaiman, M. Alyami, A. Almalik, R. Halwani, J. Merzaban, Z. Mao and N. M. Khashab, Sci. Adv., 2021, 7, eabe7174.

82 Y. Lu, W. Sun and Z. Gu, J. Controlled Release, 2014, 194, 1-19.

83 K. Rehman, M. Sajid Hamid Akash, B. Akhtar, M. Tariq, A. Mahmood and M. Ibrahim, Curr. Drug Targets, 2016, 17, 1172-1188.

84 J. Hall, S. Prabhakar, L. Balaj, C. P. Lai, R. A. Cerione and X. O. Breakefield, Cell. Mol. Neurobiol., 2016, 36, 417-427.

85 C. A. Elena-Real, A. Díaz-Quintana, K. González-Arzola, A. VelázquezCampoy, M. Orzáez, A. López-Rivas, S. Gil-Caballero, M. A. De la Rosa and I. Díaz-Moreno, Cell Death Dis., 2018, 9, 1-12.

86 L. Ding, X. Lin, Z. Lin, Y. Wu, X. Liu, J. Liu, M. Wu, X. Zhang and Y. Zeng, ACS Appl. Mater. Interfaces, 2020, 12, 36906-36916.

87 K. Kaul, M. Apostolopoulou and M. Roden, Metab., 2015, 64, 1629-1639.

88 Y. Chen, P. Li, J. A. Modica, R. J. Drout and O. K. Farha, J. Am. Chem. Soc., 2018, 140, 5678-5681.

89 Y. Duan, F. Ye, Y. Huang, Y. Qin, C. He and S. Zhao, Chem. Commun., 2018, 54, 5377-5380.

90 S. Peng, J. Liu, Y. Qin, H. Wang, B. Cao, L. Lu and X. Yu, ACS Appl. Mater. Interfaces, 2019, 11, 35604-35612.

91 S. Hager, F. J. Fittler, E. Wagner and M. Bros, Cells, 2020, 9, 2061.

92 V. Gupta, S. P. Lourenço and I. J. Hidalgo, J. Pharm. Sci., 2021, 110, 1915-1920.

93 S. Patil, Y. G. Gao, X. Lin, Y. Li, K. Dang, Y. Tian, W. J. Zhang, S. F. Jiang, A. Qadir and A. R. Qian, Int. J. Mol. Sci., 2019, 20, 5491.

94 Q. Chen, M. Xu, W. Zheng, T. Xu, H. Deng and J. Liu, ACS Appl. Mater. Interfaces, 2017, 9, 6712-6724.

95 N. Mokri, Z. Sepehri, F. Faninam, S. Khaleghi, N. M. Kazemi and M. Hashemi, Gene Ther., 2021, 149, 1-11.

96 T. Hidalgo, M. Alonso-Nocelo, B. L. Bouzo, S. Reimondez-Troitiño, C. Abuin-Redondo, M. de la Fuente and P. Horcajada, Nanoscale, 2020, 12, 4839-4845.

97 W. Wu, Y. Fan, B. Tan and H. Zhao, Microchi. Acta, 2020, 187, 1-9.

98 P. Wang, M. Xiao, H. Pei, H. Xing, S. H. Lou, C. K. Tsung and L. Li, Chem. Eng. J., 2021, 415, 129036.

99 Y. L. Balachandran, X. Li and X. Jiang, Nano Lett., 2021, 21, 1335-1344.

100 X. Li, Y. He, L. Yang, Z. He and J. J. Zhu, Chem. Commun., 2021, 57, 6776-6779.

101 A. Ringaci, A. V. Yaremenko, K. G. Shevchenko, S. D. Zvereva and M. P. Nikitin, Chem. Eng. J., 2021, 418, 129386.

102 A. Poddar, S. Pyreddy, F. Carraro, S. Dhakal, A. Rassell, M. R. Field, T. S. Reddy, P. Falcaro, C. M. Doherty and R. Shukla, Chem. Commun., 2020, 56, 15406-15409.

103 Y. Li, K. Zhang, P. Liu, M. Chen, Y. Zhong, Q. Ye, M. Q. Wei, H. Zhao and Z. Tang, Adv. Mater., 2019, 31, 1901570.

104 S. Peng, B. Bie, Y. Sun, M. Liu, H. Cong, W. Zhou, Y. Xia, H. Tang, H. Deng and X. Zhou, Nat. Commun., 2018, 9, 1-10.

105 F. Chen, M. Bai, K. Cao, Y. Zhao, X. Cao, J. Wei, N. Wu, J. Li, L. Wang, C. Fan and Y. Zhao, ACS Nano, 2017, 11, 11908-11914.

106 H. Wang, Y. Chen, H. Wang, X. Liu, X. Zhou and F. Wang, Angew. Chem., 2019, 131, 7458-7462.

107 Z. Wang, J. Niu, C. Zhao, X. Wang, J. Ren and X. Qu, Angew. Chem., 2021, 133, 12539-12545.

108 A. Poddar, J. J. Conesa, K. Liang, S. Dhakal, P. Reineck, G. Bryant, E. Pereiro, R. Ricco, H. Amenitsch, C. Doonan, X. Mulet, C. M. Doherty, P. Falcaro and R. Shukla, Small, 2019, 15, 1902268.

109 J. Zhao, D. Lu, S. Moya, H. Yan, M. Qiu, J. Chen, X. Wang, Y. Li, H. Pan, G. Chen and G. Wang, Appl. Mater. Today, 2020, 20, 100701.
110 C. P. Cerrato, K. Künnapuu and Ü. Langel, Expet Opin. Drug Delivery, 2017, 14, 245-255.

111 H. N. Abdelhamid, M. Dowaidar, M. Hällbrink and Ü. Langel, Microporous Mesoporous Mater., 2020, 300, 110173.

112 F. Liu, S. Sheng, D. Shao, Y. Xiao, Y. Zhong, J. Zhou, C. H. Quek, Y. Wang, Z. Hu, H. Liu, Y. Li, H. Tian, K. W. Leong and X. Chen, Nano Lett., 2021, 21, 2461-2469.

113 B. Mansoori, S. S. Shotorbani and B. Baradaran, Adv. Pharm. Bull., $2014,4,313$.

114 T. X. Lu and M. E. Rothenberg, J. Allergy Clin. Immunol., 2018, 141, $1202-1207$.

115 M. Acunzo, G. Romano, D. Wernicke and C. M. Croce, Adv. Biol. Regul., 2015, 57, 1-9.

116 H. Zhao, T. Li, C. Yao, Z. Gu, C. Liu, J. Li and D. Yang, ACS Appl. Mater. Interfaces, 2021, 13, 6034-6042.

117 G. R. Devi, Cancer Gene Ther., 2006, 13, 819-829.

118 C. He, K. Lu, D. Liu and W. Lin, J. Am. Chem. Soc., 2014, 136, 5181-5184.

119 M. H. Teplensky, M. Fantham, C. Poudel, C. Hockings, M. Lu, A. Guna, M. Aragones-Anglada, P. Z. Moghadam, P. Li, O. K. Farha, S. B. D. Q. Fernández, F. M. Richards, D. I. Jodrell, G. K. Schierle, C. F. Kaminski and D. Fairen-Jimenez, Chem, 2019, 5, 2926-2941.

120 J. Zhuang, H. Gong, J. Zhou, Q. Zhang, W. Gao, R. H. Fang and L. Zhang, Sci. Adv., 2020, 6, eaaz6108.

121 Y. Zhang, L. Yang, H. Wang, J. Huang, Y. Lin, S. Chen, X. Guan, M. Yi, S. Li and L. Zhang, Chem. Eng. J., 2021, 426, 131926.

122 G. Combes, I. Alharbi, L. G. Braga and S. Elowe, Oncogene, 2017, 36, 4819-4827.

123 D. Yu, M. Ma, Z. Liu, Z. Pi, X. Du, J. Ren and X. Qu, Biomaterials, 2020, 255, 120160.

124 D. Wu, Y. Gao, Y. Qi, L. Chen, Y. Ma and Y. Li, Cancer Lett., 2014, $351,13-22$.

125 J. Liu, Z. Guo, M. Kordanovski, J. Kaltbeitzel, H. Zhang, Z. Cao, Z. Gu, P. R. Wich, M. Lord and K. Liang, J. Colloid Interface Sci., 2020, 576, 356-363.

126 Y. Li, N. Xu, W. Zhu, L. Wang, B. Liu, J. Zhang, Z. Xie and W. Liu, ACS Appl. Mater. Interfaces, 2018, 10, 22974-22984.

127 J. U. Liu, Y. U. Tang, W. Yang, B. Tao, Y. E. He, X. Shen, T. Shen, C. Lin and K. Cai, Biomater. Sci., 2019, 7, 1463-1476.

128 B. Tao, C. Lin, Y. He, Y. Z. Yuan, M. Chen, K. Xu, K. Li, A. Guo, K. Cai and L. Chen, Chem. Eng. J., 2021, 423, 130176.

129 Y. Xu, Z. Li, D. Xiu, G. Sun, C. D. Snow, Y. Wang, Y. Wang, L. A. Belfiore and J. Tang, Mater. Des., 2021, 205, 109741.

130 A. Rehman, S. M. Jafari, Q. Tong, T. Riaz, E. Assadpour, R. M. Aadil, S. Niazi, I. M. Khan, Q. Shehzad, A. Ali and S. Khan, Adv. Colloid Interface Sci., 2020, 284, 102251.

131 E. Astria, M. Thonhofer, R. Ricco, W. Liang, A. Chemelli, A. Tarzia, K. Alt, C. E. Hagemeyer, J. Rattenberger, H. Schroettner, T. Wrodnigg, H. Amenitsch, D. M. Huang, C. J. Doonan and P. Falcaro, Mater. Horiz., 2019, 6, 969-977.

132 A. Migliore and S. Procopio, Clin. Cases Miner. Bone Metab., 2015, 12,31 .

133 F. Xiong, Z. Qin, H. Chen, Q. Lan, Z. Wang, N. Lan, Y. Yang, L. Zheng, J. Zhao and D. Kai, J. Nanobiotechnol., 2020, 18, 1-14.

134 M. J. Velásquez-Hernández, E. Astria, S. Winkler, W. Liang, H. Wiltsche, A. Poddar, R. Shukla, G. Prestwich, J. Paderi, P. Salcedo-Abraira, H. Amenitsch, P. Horcajada, C. J. Doonan and P. Falcaro, Chem. Sci., 2020, 11, 10835-10843.

135 M. A. Luzuriaga, F. C. Herbert, O. R. Brohlin, A. Shahrivarkevishahi, Y. H. Wijesundara, K. Veera, C. E. Benjamin, S. Popal, M. D. Burton, M. A. Ingersoll, N. J. De Nisco and J. J. Gassensmith, BioRxiv, 2021, $14,148452$.

136 J. Nawrocki, D. Prochowicz, A. Wiśniewski, I. Justyniak, P. Goś and J. Lewiński, Eur. J. Inorg. Chem., 2020, 796-800.

137 D. Prochowicz, K. Sokołowski, I. Justyniak, A. Kornowicz, D. FairenJimenez, T. Friščič and J. Lewiński, Chem. Commun., 2015, 51, 4032-4035.

138 D. Prochowicz, J. Nawrocki, M. Terlecki, W. Marynowski and J. Lewiński, Inorg. Chem., 2018, 57, 13437-13442. 